\title{
The Influence of Legitimacy on User Behavior in the Sharing Economy
}

\author{
Christine Marie Auer \\ Institute for Marketing, LMU Munich \\ c.auer@1mu.de
}

\begin{abstract}
In this paper we look at the legitimacy of sharing services as perceived by consumers and how it shapes their behavior. In doing so we shift the focus of legitimacy research that has traditionally been on investors and employees to consumers whom we identify as major stakeholders in the sharing economy and empirically investigate the impact of perceived legitimacy on consumer behavior. We conduct prescreened semi-structured focus groups and identify differentiated ways in dealing with legitimacy in the sharing economy.
\end{abstract}

\section{Introduction}

Innovation and creativity are of great importance for our society [22]. Major advances, such as the sharing economy, that have the potential to bring about enormous progress, most commonly also harbor high degrees of novelty. At the same time, this novelty and disruptive nature are the main causes for legitimacyinduced barriers [1][7][38]. Gaining legitimacy is regarded as critical for new entities which have a lack of relations, references and physical resources [39][40][24][15]. It therefore is not surprising that the major focus of legitimacy research was traditionally on its influence on investors, who function as funders and resource providers [39][40][24][15][33].

However, the impact of legitimacy on consumer behavior remains largely unexplored [24][40][39][15]. There is some research which focuses on judgement formation [4][35][5] but the actual behavior resulting from this judgement is disregarded. This is a missed opportunity since the impact of perceived legitimacy on consumer behavior is of great importance and decides whether consumers embrace or reject the organization, industry or innovation [35]. We therefore seek to find out how customers' perception of legitimacy influences their behavior in the given context of the sharing economy [39][40][24][15].

The sharing economy [3] as one of the most active and opportunity-bearing service innovations of our day and age [25] has spiked controversies among the public and the media [6][32]. Understanding the link between legitimacy and consumer behavior provides empirical substantiation of institutional theory and helps to understand customers in disruptive service industries [30]. We will introduce the theoretical fundamentals of legitimacy, provide a definition and review currently available research findings in the field of legitimacy looking at different types of legitimacy and institutional, strategic and individual-level approaches, as well as consumer behavior [24][37]. Subsequently, we will introduce the context of our empirical analysis which is constituted by service companies of the sharing economy. In our methods section, we will motivate and explain the procedures of our data collection and analysis.

We contribute to institutional theory and the research on legitimacy by analyzing the impacts of perceived legitimacy on consumer behavior. Our study helps practitioners to identify relevant control levers to achieve legitimacy to effectively drive consumer behavior and increase the chances of long-term success of new firms in the sharing economy.

\section{Literature review}

Organizations are part of a network of stakeholders to which they are linked with bilateral relationships. This generates a co-dependence between them which is essential for their ongoing subsistence. All relationships are marked by exchange. A simple example is when an organization provides services and goods and customers provide money for them in return [17]. In other, more complex, interdependences, stakeholders provide the creation and maintenance of legitimacy to organizations and other entities. Suchman's comprehensive definition of legitimacy as "a generalized perception or assumption that the actions of an entity are desirable, proper, or appropriate within some socially constructed system of norms, values, beliefs, and definitions, (p. 574) [33]" integrates institutional theory and management strategy [33] and has become the most commonly accepted 
definition. It is important to note that these two approaches, the institutional theory perspective [28][26] and the strategic management perspective [2][12] have significant differences in their underlying reasoning. In institutional theory where the focus is on "collective structuration" (p. 148) [27] and holistic sector or industry dynamics [33], the entity cannot shape the legitimation process because it is subject to its environment and its own framework structure. How it is perceived, made sense of and evaluated is determined by cultural definitions [33]. As a result, legitimacy can only be defended and supported by adhering to already approved setups and processes [10][26]. In the strategic perspective, by contrast, legitimacy is regarded as an operational tool with which managers can actively control realization processes [33]. To reconcile the different approaches provided by the divergent research traditions of institutional theory and strategic management, researchers have developed the understanding that there is a variety of intersecting legitimacy types or dimensions that vary strongly depending on each specific context or domain while also bearing similarities across their individual meanings. First attempts to theorize these communalities and differences are brought forward by Aldrich and Fiol [1] who differentiated between cognitive and sociopolitical legitimacy. Cognitive legitimacy, also known as cultural-cognitive legitimacy, refers to how wellknown and understood an entity is within its environment by adhering to cognitive schemes and cultural reference frames [1][31][33]. Sociopolitical legitimacy is the congruence with universally approved values, norms, rules and standards which leads important stakeholders such as the general public, opinion leaders or the state to evaluate the entity as proper and desirable. Tying in with this is Scott's [31] further specification of sociopolitical legitimacy as having either a normative or a regulative function. Scott's [31], regulative legitimacy indicates that the entity is "operating in accordance with relevant legal or quasi-legal requirements" (p. 74) [31] whereas normative legitimacy is established if the entity follows pre-existing social norms and values which Scott summarizes as normative rules [31][29]. Hunt and Aldrich [23] build on this framework and provide an integrated version for which they define cognitive legitimacy, sociopolitical regulatory legitimacy and sociopolitical normative legitimacy. Hunt and Aldrich's [23] cognitive legitimacy is equivalent to the cognitive legitimacy in Suchman's landmark work. Suchman's moral legitimacy can be regarded as a part of sociopolitical normative legitimacy [33][9] and his pragmatic legitimacy is comparable to sociopolitical regulatory legitimacy.
Attempts to operationalize legitimacy are limited and empirical evidence remains scarce [33][38][14]. Among the pioneers of empirical research on legitimacy is Kimberly Elsbach [13] who drew on surveys and experimental methods to investigate how individuals made legitimacy judgements based on responses to verbal accounts in the context of the California cattle industry. As mentioned in the previous section on outcomes to legitimacy, Elsbach [13] integrated institutional research with impression management theories. She developed and tested a scale that measures legitimacy, from the perspective of the general public on an individual level, with the help of twelve items that load into the three factors "normativity", "support by employees" and "support by general public" (p. 78). It is her scale after which we will model our prescreening and the legitimacy component of our interview guidelines.

In conclusion, the literature review above lets us see that consumers are likely to base their legitimacy judgements on a pragmatic, moral and cognitive dimension [33]. Following this judgement process, consumers define for themselves a generalized evaluation of legitimacy which follows a continuous spectrum which is positive if above neutral and negative if below neutral [35]. We argue that, while this relation has not been empirically investigated, it is an over-simplification on how legitimacy affects consumer behavior. We argue that a multi-faceted approach is needed to grasp actual outcomes to discover how legitimacy assumptions influence behavior. While most studies concentrate on the legitimacy judgement rather than on the subsequent behavior that it may induce, there is also a lack of research on consumer perceived legitimacy in general [33][38]. This paper seeks to address this research gap which appears to be a promising continuation on the long tradition of legitimacy research and aims at working out managerial implications that are particularly interesting to marketers and consumeroriented scholars.

\section{Context: Sharing economy}

Our context is the fast-rising trend of the sharing economy which is known for its disruptive nature and has evoked change in traditional markets at a rapid pace. The scope of its platforms and the number of operators has expanded in the last few years and has attracted more and more players in almost any industry [18]. Not only the sharing economy but also the criticism evolving around it is constantly growing. A variety of different stakeholders such as government officials, the general public and opinion leaders such as 
the media utter their conceptions and engage in a heated debate about the activities and the raison d'être of platforms which bring together mostly private persons on a daily basis for the exchange of consumer goods. At its core is the collaborative consumption of goods through multiple persons and the improved use of available capacities to protect important resources. Having grown over several years, the sharing economy has become multifaceted and includes the sharing of cars, rooms, food and almost all areas of life. According to the European Commission, there exist three different platforms in the sharing economy which include the recirculation of goods, increased asset utilization, and service and labor exchanges [8]. We are mostly interested in the category of increased asset utilization which are represented by "classical peer-topeer (P2P, i.e., Uber, Airbnb, TaskRabbit, etc.) [platforms] where the peers are natural persons" (p. 11) [8]. What makes classical peer-to-peer platforms particularly interesting for examining the relationship between legitimacy and user behavior is that the sharing economy is confronted with continuing challenges to its legitimacy. Service providers in the sharing economy are subject to legal uncertainty and vulnerable to potential regulatory constraints across the globe. This is due to the fact that their offerings include disruptive technologies which allows millions of people to use services that are not covered by the current legal and regulatory frameworks [19][20]. The controversies that surround peer-to-peer platforms which are heavily discussed in the media and the general public lead to an increased awareness among consumers. Having created novel market places, especially in the hospitality, consumer goods, transportation and mobility industries [18], they are widely known to lie at the focus of policy formation and regulations. At the same time, competition in the sharing economy has highly increased with high valuations, large numbers of customer and users and investors mobilizing immense sums of money for promising business models [34]. We can see that there are advantages as much as there are disadvantages and risks and likewise that there is skepticism while there are still large numbers of users flocking to shared services. This phenomenon cannot be explained by the current theory on legitimacy and must therefore be regarded through a more nuanced perspective on individuals' motivations and deterrents.

\section{Empirical study}

We have taken an iterative approach combining the qualitative methods of focus groups and interviews [16] which are well suited to capture subjective opinions. Before admission to participation, individuals completed our pre-screening questionnaire, which includes Elsbach's [13] legitimacy scale as well as user behavior, intentions to use and frequency of use. Our focus groups and individual interviews have yielded a total of 24 hours of interview material with an average length of 48 minutes each.

For both the focus groups and the interviews, we have used semi-structured guidelines which contain an introduction phase, three different structured parts and a final open part. In the first part, all participants were asked about their understanding of the sharing economy. The second part involved the participants' descriptions of their user behavior. In the third part interviewees and discussants were asked to elaborate on how different aspects of the sharing economy influenced their behavior. The corresponding set of questions was based on Elsbach's [13] scale to measure legitimacy and included service quality, compliance with industry standards, media coverage, environmental considerations and the future relevance of the products and services of the sharing economy. After each manifestation of legitimacy, which is reflected by Elsbach's twelve items [13], we have asked the individual what role it plays for them, how they judge its status quo and how this is relevant for their behavior in terms of use, frequency of use, recommendation and attitude.

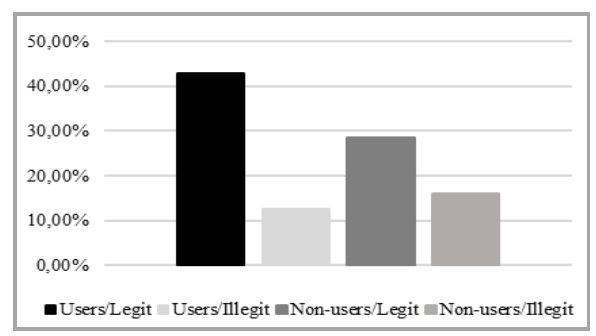

Figure 1. Distribution of participants

\section{Results}

We have applied a coding process that closely resembles the category building after Gioia, Corley and Hamilton [21]. Based on the categorization in our literature review above, we have ascribed evidences to pragmatic, moral and cognitive legitimacy. Please note that we did not find antecedents for not using shared services in spite of perceived pragmatic legitimacy. It is worth noting that whenever traditional services are mentioned, individuals mostly refer to taxis and other means of transportation when they talk about shared mobility services as well as bed and breakfasts and hotels when they speak of shared hospitality services. 


\subsection{Pragmatic legitimacy}

5.1.1 Pragmatic antecedents for not using the service. Among the reasons to not use shared services are financial considerations. Individuals have also perceived shared services as potentially harmful to their person. Furthermore, they are concerned about inconsistencies in quality. Other reasons are a focus on personal downsides and the specific predisposition of the individual. Individuals believe in their personal upsides when using alternatives and are unsure who is in charge if something happens. Pragmatically motivated non-users demonstrate reservations against sharing providers and are concerned about systemic flaws. The general notion that shared services operate at the brink of legality brings forward personal reasons for non-use. Some individuals experience no need, occasion or opportunity to use shared services.

\section{Table 1. Pragmatic antecedents for non-use}

\begin{tabular}{|ll|}
\hline Non-use because of pragmatic illegitimacy \\
\hline - Financial considerations & - Questions of liability \\
- Harmful to the individual & - Reservations against providers \\
- Inconsistency of quality & - Systematic flaws \\
- Personal downsides & - Personal impact of illegality \\
- Personal predisposition & - There is no need, occasion or \\
- Personal upsides of alternatives & opportunity to use \\
\hline
\end{tabular}

5.1.1 Pragmatic antecedents for using the service. A pragmatically motivated reason to use shared services is the affordability and accessibility of experiences. Pragmatic users stress that shared services are superior to competitors. Some select the best option upon availability and consider country specific aspects. Shared services are associated with freedom. Pragmatically motivated users state that their likelihood to use increases if the service is more professional. Individuals state that they perceived shared services as the safer option. While use is oftentimes motivated by need, there are personal attributes that are brought forward as reasons to use. Shared services benefit from the perceived shortcomings of traditional providers and are perceived to have a higher social entertainment value. Individuals are especially inclined to use them if they do not impact their private sphere. They moreover appreciate the transparency of the service and confirmed their trust in the rating system. Finally, the user-friendliness of shared services makes the service convenient.

Individuals sometimes use the service in spite of reasons that make it illegitimate from a pragmatic point of view (P3). The service is used in spite of the fear of data misuse. Individuals concede that there may be consequences to their personal safety and are willing to use a service with an uncertain standard.
Table 2. Pragmatic antecedents for use

\begin{tabular}{|l|l|}
\hline $\begin{array}{l}\text { Use because of pragmatic } \\
\text { legitimacy }\end{array}$ & $\begin{array}{l}\text { Use in spite of pragmatic } \\
\text { illegitimacy }\end{array}$ \\
\hline - Affordability and accessibility of \\
$\begin{array}{l}\text { experiences } \\
\text { - Benefits and superiority over } \\
\text { competitors }\end{array}$ & $\begin{array}{l}\text { - Data misuse } \\
\text { - Personal safety } \\
\text { - Uncertain standard }\end{array}$ \\
\cline { 2 - 2 } - Constant selection of best option & - Shortcomings of traditional \\
- Country specific aspects & providers \\
- Freedom for the user & - Social entertainment value \\
- Level of professionality & - Specific situations \\
- Matters of personal safety & - Transparency \\
- Need for using the service & - Trust in the rating system \\
- Personal attributes & - User-friendliness \\
\hline
\end{tabular}

\subsection{Moral legitimacy}

5.2.1. Moral antecedents for not using the service. There are several moral aspects that deter individuals from using shared services. Among the reasons are how companies deal with existing rules, environmental concerns and perceptions of justice and fairness. Individuals state that the level of professionalization and commercial activity matters and that they are concerned about the local business community. Individuals have uttered apprehensions of negative future developments and problems with corporate governance. The role of the government and whether individuals feel that providers are treated badly and are exploited are relevant influences. Individuals who are deterred on moral grounds are very concerned about the weakening of the system through disruptive change.

\section{Table 3. Moral antecedents for non-use}

\begin{tabular}{|l|l|}
\hline $\begin{array}{l}\text { Non-use because of moral } \\
\text { illegitimacy }\end{array}$ & $\begin{array}{l}\text { Non-use in spite of moral } \\
\text { legitimacy }\end{array}$ \\
\hline - Dealing with existing rules \\
- Environmental considerations \\
$\begin{array}{l}\text { - Justice and fairness } \\
\text { - Level of professionalization and } \\
\text { commercial activity }\end{array}$ & $\begin{array}{l}\text { - Environmental benefits } \\
\text { - Situational differentiation }\end{array}$ \\
\cline { 2 - 2 } $\begin{array}{l}\text { - Local considerations benefits } \\
\text { - Negative future development } \\
\text { - Problems with corporate } \\
\text { governance }\end{array}$ & $\begin{array}{l}\text { - Role of government } \\
\text { Treatment of providers }\end{array}$ \\
\hline
\end{tabular}

Some individuals acknowledge morally positive aspects but refrain from use in spite of them. Among those are environmental benefits that some individuals stated are not strong enough to guide their behavior. Although individuals differentiate between more and less harmful situations and believe in social benefits, they generally oppose to using these services.

5.2.2. Moral antecedents for using the service. Reasons to use when considering moral antecedents include case specific aspects and future considerations, 
as well as, individuals' perspectives on disruption and innovation. A belief in the positive impact on society and the environment are further reasons. Individuals do not believe to cause a noticeable difference when using the services and brought forward personal attributes. They also claim to appreciate the potential for noncommercial models and are motivated by support for smaller players. What regulation and legality mean to individuals also has an influence on their decision.

\section{Table 4. Moral antecedents for use}

\begin{tabular}{|l|l|}
\hline Use because of moral legitimacy & Use in spite of moral illegitimacy \\
\hline - Case-specific considerations & - Consumer social responsibility \\
- Considerations concerning future & - Detachment from need for \\
- Disruption and innovation & improvement \\
- Impact on society & - Dismissal of current regulations \\
- Impact on the environment & - Fluctuation and discontent \\
- No noticeable difference & - Frequency and impact of individual \\
- Personal attributes & use \\
- Potential for non-commercial & - Full-time job or side lining \\
models & - Hope for improvement \\
- Support for smaller players & - Means of self-regulations \\
legality & - Outweighed by self-interests \\
\hline - Affordable offers & - Political resistance \\
- Adverse feelings and likability & - Situational aspects \\
\hline
\end{tabular}

There are moral aspects that individuals do not endorse but that do not deter from using a service. A major reason is the affordability of offers. Individuals also state that they use a service in spite of adverse feelings and unlikability. Even when morally opposed to a service, individuals do not have a sense of responsibility. In spite of several reasons featuring the need for improvement in terms of environmental concerns, future development and negative impacts on a certain region, individuals state that would use the service. This is also the case if it goes against current regulations which the individual disagrees with. Problematic but not a deterrent are high rates of fluctuation and discontent among providers. Infrequent use and low impact of individual use and the lack of seriousness of providers as professional jobs are further reasons. Individuals use the services of companies in the hope of future improvement. Using shared services in spite of a lack of regulation is acceptable since individuals feel able to make their own choices. Furthermore, individuals use a service that they find morally inacceptable if the downsides are outweighed by their own self-interests. Political resistance has no effect on individuals who state that their awareness of disruption does not prevent their use. Individuals are more willing to use a new, uncertain service when they have no time constraints and use morally questionable services in situations of urgency. Individuals state that they would use a service if the company does not pay taxes and some find that the company's paying lower taxes is advantageous for the end consumer.

\subsection{Cognitive}

5.3.1. Cognitive antecedents for not using the service. There is a variety of reasons why individuals do not use shared services that can be attributed to a lack of cognitive legitimacy. Among them is that looking things up online is not enjoyable, there is no confrontation with the service or it is not transparent enough to gain an understanding of it. An individual's attributes can explain reservations. A negative image or representation in the media and online can function as a deterrent. Some individuals do not have smartphones and applications. Individuals also base their decision on negative personal experiences. In specific situations, individuals use their experiences to differentiate between services making the strength of alternatives a reason to not use. The social surrounding and not being taken have a strong influence.

\section{Table 5. Cognitive antecedents for non-use}

\begin{tabular}{|c|c|}
\hline $\begin{array}{l}\text { Non-use because of cognitive } \\
\text { illegitimacy }\end{array}$ & $\begin{array}{l}\text { Non-use in spite of cognitive } \\
\text { legitimacy }\end{array}$ \\
\hline \multirow{2}{*}{$\begin{array}{l}\text { - Dealing with new things } \\
\text { - Exposure and knowledge } \\
\text { - Individual attributes } \\
\text { - Negative image } \\
\text { - Negative representation } \\
\text { - No technical means } \\
\text { - Personal experience } \\
\text { - Situational aspects }\end{array}$} & $\begin{array}{l}\text { - Positive experiences of friends and } \\
\text { family } \\
\text { - Use of similar services } \\
\text { - Willingness to try }\end{array}$ \\
\hline & $\begin{array}{l}\text { - Strength of alternatives } \\
\text { - Surrounding individuals } \\
\text { - Taken for granted status }\end{array}$ \\
\hline
\end{tabular}

There also subsist are variety of cognitive reasons not to use shared services in spite of their perceived legitimacy. Individuals voice that they will not use a service in spite of positive experience made by friends and family or in the presence of established models that the individual is familiar with. The willingness to try new things is overwhelmed by old habits.

5.3.2. Cognitive antecedents for using the service. Among the cognitive reasons to use a shared service is that the individual has successfully built a mental image and is willing to deal with novelty and uncertainty. The influence of friends, family and other contacts also plays a major role. Related experiences promote the use of new services. Non-personal social influences and personal experiences play important roles.

\section{Table 6. Cognitive antecedents for use}

\begin{tabular}{|c|c|}
\hline Use because of cognitive legitimacy & $\begin{array}{l}\text { Use in spite of cognitive } \\
\text { illegitimacy }\end{array}$ \\
\hline \multirow{2}{*}{$\begin{array}{l}\text { - Building a mental image } \\
\text { - Dealing with novelty and } \\
\text { uncertainty } \\
\text { - Influence of friends, family and } \\
\text { other contacts } \\
\text { - Influence of related experiences }\end{array}$} & $\begin{array}{l}\text { - Bad experiences } \\
\text { - Low interest in adverse information } \\
\text { - Negative media attention } \\
\text { - Trendiness }\end{array}$ \\
\hline & $\begin{array}{l}\text { - Non-personal social influences } \\
\text { - Personal experiences }\end{array}$ \\
\hline
\end{tabular}


Lastly, some interview answers explain why individuals will use a service in spite of cognitive illegitimacy. Individuals continue using a service in spite of bad experiences, depict low interest in adverse information and do not consider negative media attention. The fading hipness of shared services is overruled by their convenience.

\section{Discussion and conclusion}

In the following we will discuss the theoretical and practical implications of our findings and provide directions for future research.

\section{1. Theoretical implications}

6.1.1. Influence or no influence of legitimacy and illegitimacy on user behavior. We can generally see that consumers with higher levels of perceived legitimacy are more open to becoming users of shared services. We also noted that shared services suffer from deficient legitimation which, in some cases, leads to a loss of confidence among consumers and causes them to deliberately refuse their participation in shared services. In line with the extant literature we agree that it appears to be in companies' best interest to work on an efficient legitimation strategy.

Nevertheless, there are also situations in which legitimacy does not lead to use and illegitimacy does not deter use. Some individual cannot afford the service and do not engage in online business. In some situations, the service is simply not available in the individual's region. A missing influence of certain types of illegitimacy on user behavior also becomes apparent when consumers prioritize their own needs, that are based on pragmatic legitimacy, over a certain principle representing moral legitimacy. These pragmatic reasons may not always reflect an individual's moral standpoint.

6.1.2. Different legitimacy assumptions and their meaning. We find that we cannot view legitimacy and user behavior as entirely different entities. There are clear differences in how legitimate shared services are perceived by different individuals. Some inseparable correlations affect both sides of this equation. These may be person specific and are not traditionally accounted for as legitimacy inducing. Among these are the judgement of the status quo of traditional companies and extant structures and the influence this judgment has on a consequential judgement of disruption. In some cases, where individuals perceive the disruption of the traditional industry as beneficial, the disruptive nature of shared services can have confirmative effects on consumers' user behavior. How individuals feel about the status quo has a strong impact on how they judge the disruptive nature of shared services. This is influenced by person-specific aspects. Differences may be based on the individual's political opinion. Socially-oriented individuals may believe in heavier regulation. Liberally-oriented individuals might prefer self-regulations by the citizens and favor freedom over protection. This also influences the extent of trust in the ability of providers to make their own decisions. Moreover, individuals with a stronger sense of individualism may be more likely to attribute higher degrees of legitimacy to the sharing economy and are more likely to use its services. Individuals' willingness to adapt to change and generally low trust in unfamiliar situations may also be embedded in some individuals' personalities.

6.1.3. Construal level of moral legitimacy and license to compete. Moral concerns mostly stem from the media or online sources. The arguments that were provided based on moral legitimacy often occur on a hypothetical level. Individuals tend to leave their firstperson narrative and switch to a more abstract third person, e.g. "one should...". This indicates that these considerations occur on a more distant construal level [36]. Individuals with a more myopic outlook are focused on direct, pragmatic gains, whereas less myopic, moral concerns require the ability to account for more distant effects and to produce a less myopic vision of the future. Individuals also noticeably switched their arguments depending on which identity's perspective they were taking. There is a distance between individuals in their identity as end consumers and their identity as observers of macro outcomes. An individual could e.g. not only recognize lower taxes as a myopic gain for the consumer but also as a downside for society on the long run.

A similar phenomenon appears to revolve around the fact that some individuals are very sensitive to what they consider unfair competition. Donaldson and Preston describe the relation of competition and consumers in the following way: "As a result of competition throughout the system, the bulk of the benefits will go to the customers" [1011] (p. 68). What we have observed, however, is that individuals oppose disruptive forms of competition even if this is, myopically considered, against their own advantage.

6.1.4. Cognitive legitimacy, lack of knowledge and initial use. Individuals tend to ascribe more risk to unfamiliar things. Expecting the worst functions as a default. Examples of this phenomenon are statements that sharing providers are generally unreliable or that the service is unreliable even if individuals have not 
used the service themselves. Ironically, in order to achieve cognitive legitimacy, new business models and ventures need established structures which at the same time inhibits deviation from established structures. Individuals become "stuck in ignorance" because they do not have knowledge about a service and therefore will not use a service and will not gain new knowledge in turn. Individuals who have no own experiences with a service to draw on are less willing to gain experiences. We may be able to solve this conundrum by turning to the social environment. This appears to play a large role for the initiation of use. The point at which a customer actively engages with a service is oftentimes heavily influenced by familiar people. Initially getting into personal touch with a service is anteceded by some influence of authenticity. Almost all of our users have initially tried out the service because they were influenced by people they regard as authentic. These do not need to be close to the individual. Other people using the services or a general social acceptance together with the service being perceived as very public suffices.

Initiation can also be made more approachable if the service has credible similarities to other services that the individual has already made personal experiences with. Prior knowledge of an associated brand may function as an authentic indicator when own experience can be ascribed to it. Along this line is that individuals appear to be willing to initially try out a service with someone else who agrees that this is a good idea. For practitioners this means that for services with unclear legitimacy, direct advertisement is probably less effective than word of mouth.

Convenience is key when motivating an individual to try out a service especially if there is no prior experience. Individuals have stated that informing themselves is cumbersome but especially experiences by friends reduce the need for them to inform themselves. They can replace research by accounts from authentic examples. There is an external push and pull in which the sharing of bad experiences and recommendations induces non-use and vice versa. Online and media influences, are perceived as less authentic, virtual accounts and are more effective if used negatively. Some individuals who are generally not convinced by the service because they are strongly morally opposed to it and even authentic accounts will remain ineffective. Interestingly recovery from a bad experience appears to be easier than motivating someone to use the service for the first time.

6.1.5. Notions of responsibility and commitment, deviation and conformity. The notion of responsibility appears to be crucial. Oftentimes it is assigned to friends, the state or the provider. This is also indicated by the willingness to use a service with other people and not alone. Almost as if, in case it turns out to be a bad idea, the burden of engaging in something new is socially shared. In some cases, the responsibility of making a good decision in choosing for or against an unknown service seems to be more important than the actual harm this decision may entail. This is a way of distributing responsibility which is surprising given the low degree of commitment involved in initiating most shared services. Individuals are also trying to deflect responsibility and commitment by reducing the frequency and regularity of their use whenever they perceive a service to be morally illegitimate.

Most individuals are deterred from illegality entirely and make the decision to use or not use dependent on the state's decision after a final evaluation. They postpone the decision to use and then behave accordingly after the state has decided. and thus place the decision to use in the hands of the state who would decide for them by legalizing or prohibiting a shared service company. However, there is also willingness to remain uninformed about the status of shared services. Appreciating that the service is in line with where the future development is headed anyway is another group aspect and indicates the influence of the social group and environment.

6.1.6. Lock in-phenomenon and subscription. Although it can actually be as little as a one-time use case, individuals appear to regard the choice of using a new service as a major situation, even when there is no contractual lock-in involved. Individuals appear to construct a mental subscription model and, to them, the service either becomes the default option or no option at all. This phenomenon works in both directions. Those who describe themselves as being caught in old habits stay in their perceived lock-in with their traditional provider. Others perceived the switch to a new provider as a larger commitment. Once an individual's habits have reversed, the commitment appears to have switched from the focal provider to the previously non-focal competitor. In some cases, this commitment is strong enough for individuals wanting to ignore adverse information. It is worth noting that this effect may in part be due to the situation of the interview or focus group in which individuals seek to portrait a consistent image of themselves.

6.1.7. Flexibility of thinking and willingness to be informed. Individuals who care about moral concerns tendentially appear to be more informed citizens. Nevertheless, there are also individuals who generally oppose of shared service because they find them morally illegitimate even if there are sometimes also 
morally beneficial aspects. These individuals may engage in some form of simplification, or regard behavior that is opposed to their locked-in opinion as threat to their identity. It may also be a shortcut to making decisions anew for each situation depending on the relative circumstances, such as accepting that specific individuals have things under control in spite of absent regulations, which requires a greater flexibility of thinking. Very few take on self-regulating what they perceive as unfair e.g. giving a driver a higher tip to make up for lower wages. A greater effort of appraising situational risks can be observed where there is higher social value because a service is beneficial to small players and underdogs when the user does not ultimately depend on the service. At the same time in situations where the user depends on the quality and reliability of the service more trust is place in the hands of larger corporations.

6.1.8. Hierarchy of legitimacy dimensions. There appear to be uneven power dynamics between the different legitimacy dimensions. Identifying the hierarchy of different influences is an interesting research problem and requires investigating which legitimacy dimensions influence and override others. Moral arguments appear to be sometimes overridden by more myopic rational motivations. At the first glance, this is motivated by personal benefits. Nevertheless, moral arguments that are in favor of using shared services may also be strategically referred to in order to support behaviors that are motivated by pragmatic or cognitive lock-in and are in line with what the individual wants to do based on individual benefits or out of habit. Our findings have revealed that the most influential stakeholders are other consumers. We therefore propose that cognitive legitimacy is the decisive factor and that additional arguments are designed in support of the decision that was already made by the individual.

\subsection{Managerial implications}

Based on our results, we can derive several implications for practitioners. While most individuals would appreciate more control, sometimes these aspects threaten the sheer essence of "sharing" and a complete adjustment would render these services no different from extant, traditional services. We have discovered that while some individuals may not be suitable customers for informal shared services. There appear to be two broader groups. Users either prefer more personal or more professional services. On the one hand, individuals appear to accept that services which are comparable to more personal experiences, e.g. with friends and acquaintances, in which they take on the role as guests are less regulated and standardized. On the other hand, for services that are more comparable to traditional, professional services, with which they assume the role of an ordering party, the same level of standard and regulations as with said comparable services is expected. Therefore, more professional, money making oriented services require more quality assurance and regulations than their less commercialized counterparts. We find that sharing platforms have two distinct choices on both extremes of the spectrum but less of a middle ground since everything falling in between those two options appears to be considered as either inauthentic or unreliable. Sharing services therefore are advised to avoid the situation of being stuck in the middle.

General trust in online business and the reliability of the rating system are decisive factors. Customers are willing to let companies use their data if they associate value to it. Nevertheless, data protection is important and even if individuals are getting used to providing personal information, their awareness of misconduct is also increasing. Transparency and good conduct in this area are appreciated and could soon become an important criterion that could be turned into a unique selling point, or, if not sufficiently addressed, a knockout criterion. Individuals, while appreciating a more personal, authentic service, nevertheless mostly appreciate the anonymity that comes with online sharing services. They do not want personal habits to be known by strangers. Even if some individuals like to build up business relations with service providers, others enjoy a more anonymized experience which provides another opportunity for differentiation.

As the sharing economy is becoming more established, new entities emerge and competitive behavior becomes apparent. With market maturation, individuals become more informed about the concept, making it easier to become taken for granted, but at the same time, individuals become more sensitive to differences between providing companies and actively decide in favor of those who not only fulfil pragmatic purposes but are also in line with regulations and moral aspects. As the luxury of choice is introduced due to the entering of more and more competitors, corporate social responsibility is gaining in importance.

\subsection{Limitations and future research}

The interpretative nature of our qualitative approach presents an opportunity for future research in which the findings of this study can be continued in a questionnaire and evaluated on a larger, representative scale. Since we took a qualitative approach we have no guarantee of whether our arguments are generalizable and whether they are more likely to cooccur under 
certain circumstances or to how many people they apply. We nevertheless present motivations that are grounded in illegitimacy or legitimacy considerations that were put forward by real life participants. Regarding this matter we also have to keep in mind that our findings are based on retrospective accounts and not on actual behavior. This limitation could be addressed by conducting further research in the form of experiments or even field experiments. Another critical aspect is the general nature of our research approach. We have taken a broader view on the sharing economy and included different forms in our conversations with individuals. Future studies could take a more focused approach to find solutions that specifically address different niches of the sharing economy.

We recommend investigating the power dynamics between different legitimacy dimensions. Researchers could compare the findings in this study to other types of products and in situations of varying perceptions of risk. There is a considerable risk of participating in shared services for mobility and hospitality as individuals may be in danger if providers are not trustworthy. Comparing this to situations where this potential threat is reduced, e.g. by working with professionals, may shed further light on this matter. Another interesting aspect to investigate further is the degree of psychological distance that may vary between the different dimensions of legitimacy. Researchers could moreover look into how far an individual is removed from a certain situation when pragmatically or cognitively motivated as opposed to how emotionally close he feels when he is influenced by ideological and moral motivations. Given our delineations above, we moreover recommend taking on the studying of first time use as a separate, interesting and challenging research opportunity for examination.

\subsection{Conclusion}

This paper has investigated how consumers' perceptions of legitimacy shapes and influences their behavior on the example of the sharing economy. We have followed a qualitative approach to gain multifacetted insights to analyze the perspective of the important stakeholder group of consumers. We hope this study will trigger more research in this field. Our findings have been edited to match the format of this manuscript. An overview of our data structure is available on request.

\section{References}

[1] Aldrich, H. E., and C. M. Fiol, "Fools rush in? The Institutional Context of Industry Creation", Academy of Management Review, 19 (4), 1994, pp. 645-670

[2] Ashforth, B. E., and B. W. Gibbs, "The Double-edge of Organizational Legitimation”, Organization Science, 1 (2), 1990, pp. 177-194

[3] Belk, R., "You are what you can access: Sharing and collaborative consumption online", Journal of Business Research, 67(8), 2014, pp. 1595-1600

[4] Bitektine, A., "Toward a theory of social judgments of organizations: The case of legitimacy, reputation, and status", Academy of Management Review, 36 (1), 2011, pp. 151-179

[5] Bitektine, A., and P. Haack, "The 'macro' and the 'micro' of legitimacy: Toward a multilevel theory of the legitimacy process", Academy of Management Review, 40(1), 2015, pp. $49-75$

[6] Brauns, B., "Lobbyismus mit der Crowd", Zeit Online, Nov 4, 2016, available from: http://www.zeit.de/wirtschaft/unternehmen/2016-10/airbnbgesetze-ferienwohnungen-sharing-economy/komplettansicht

[7] Chua, R. Y. J., Y. Roth, and J.-F. Lemoine, "The impact of culture on Creativity: How cultural tightness and cultural distance affect global innovation crowdsourcing work", Administrative Science Quarterly, 60, 2015, pp. 189-277

[8] Codagnone, C, B. Martens, "Scoping the Sharing Economy", European Commission JRC Technical Reports, Jan 2016, pp. 1-34

[9] Deephouse, D. L., and M. Suchman, "Legitimacy in Organizational Institutionalism”, R. Greenwood, C. Oliver, R. Suddaby, and K. Sahlin, The SAGE Handbook of Organizational Institutionalism, Sage, Thousand Oaks, 2008, pp. $49-77$

[10] DiMaggio, P., and W. W. Powell, "The iron cage revisited: Collective rationality and institutional isomorphism in organizational fields", American Sociological Review, 48(2), 1983, pp. 147-160

[11] Donaldson, T., and L. E. Preston, "The Stakeholder Theory of the Corporation: Concepts, Evidence, and Implications", The Academy of Management Review, 20(1), 1995, pp. 65-91

[12] Dowling, J., and J. Pfeffer, “Organizational legitimacy: Social values and organizational behavior", Pacific sociological review, 18(1), 1975, pp. 122-136

[13] Elsbach, K., "Managing Organizational Legitimacy in the California Cattle Industry: The Construction and Effectiveness of Verbal Accounts", Administrative Science Quarterly, 39 (1), 1994, pp. 57-88 
[14] Finch, D., D. Deephouse, and P. Varella, "Examining an Individual's Legitimacy Judgment Using the Value-Attitude System: The Role of Environmental and Economic Values and Source Credibility”, Journal of Business Ethics, 127(2), 2015, pp. 265-281

[15] Fisher, G., S. Kotha, and A. Lahiri, "Changing with the times: an integrated view of identity, legitimacy, and new venture life cycles." Academy of Management Review, 41(3), 2016, pp. 383-409

[16] Flick, U. Introducing Research Methodology: A Beginner's Guide to Doing a Research Project. Sage, Thousand Oaks, 2011

[17] Freeman, R. E. Strategic management: A stakeholder approach, Pitman, Boston, 1984

[18] Freese, C., and A. T. Schönberg, "Shared Mobility. How New Businesses Are Rewriting the Rules of the Private Transportation Game”, D. Horstkötter, Roland Berger, Munich, 2014

[19] Frey, T. (2014): "The Disruptive Nature of the Sharing Economy: Finding the Next Great Opportunities", Futurist Speaker, Feb 1, 2014

[20] Geron, T., "Airbnb and the Unstoppable Rise of the Share Economy”, Forbes, Jan 23, 2013

[21] Gioia, D., K. Corley, and L. A. Hamilton, "Seeking Qualitative Rigor in Inductive Research", Organizational Research Methods, 16, 2013, pp. 15-31

[22] Godart, F. C., W. W. Maddux, A. V. Shipilov, and A. D. Galinsky, "Fashion with a foreign flair: Professional experiences abroad facilitate the creative innovations of organizations", Academy of Management Journal, 58(1), $2015,195-220$

[23] Hunt, C. S., and H. E. Aldrich, "Why even Rodney Dangerfield has a home page: Legitimizing the world wide web as a medium for commercial endeavors", presented at AOM, Cincinnati, 1996

[24] Lounsbury, M., and M. A. Glynn, "Cultural entrepreneurship: Stories, legitimacy and the acquisition of resources" Strategic Management Journal, 22(6/7), 2001, pp. $545-564$

[25] Lu, C. and J. Kandampully, "What drives customers to use access-based sharing options in the hospitality industry?", Research in Hospitality Management, 6 (2), 2016, pp. $119-126$

[26] Meyer, J. W., and B. Rowan, "Institutionalized organizations: Formal structure as myth and ceremony", American Journal of Sociology, 83(2), 1977, pp. 340-363
[27] Powell, W. W., and P. J. DiMaggio, "The Iron Cage revisited: Institutional Isomorphism and collective Rationality in organizational Fields", American Sociological Review, Vol. 48, 1983, pp. 147-160.

[28] Powell, W. W., "Expanding the Scope of Institutional Analysis", W. W. Powell, P. J. DiMaggio, The New Institutionalism in Organizational Analysis, University of Chicago Press, Chicago, 1991, 183-203

[29] Ruef, M., and W. T. Scott, "A multidimensional model of organizational legitimacy: Hospital survival in changing institutional environments", Administrative Science Quarterly, 1998, pp. 877-904

[30] Schor, J. B., and C. J. Fitzmaurice, "Collaborating and connecting: The emergence of the sharing economy”, L. A. Reisch, J. Thøgersen, Handbook of Research on Sustainable Consumption, Edward Elgar, Cheltenham, 2015, pp. 410-425

[31] Scott, W. R. "Institutions and organizations", Sage, Thousand Oaks, 1995

[32] Stern. "Uber: Hacker stahlen Daten von 57 Millionen Nutzern und Fahrern.", Nov 22, 2017

[33] Suchman, M. C., "Managing legitimacy: Strategic and institutional approaches", Academy of management review: 20(3), 1995, pp. 571-610

[34] The Economist (2013): "All Eyes on the Sharing Economy", Mar 9, 2013

[35] Tost, L. P., "An integrative model of legitimacy judgments", Academy of Management Review, 36(4), 2011, pp. 686-710

[36] Trope, Y., and N. Liberman, N., "Construal-Level Theory of Psychological Distance", Psychological Review, 117 (2), 2010, pp. 440-463

[37] Überbacher, F. "Legitimation of New Ventures: A Review and Research Program", Journal of Management Studies, 2014, 51 (4), pp. 668-698

[38] Vergne, J. P., "Toward a new measure of organizational legitimacy: Method, validation, and illustration", Organizational Research Methods, 14(3), 2011, pp. 484-502

[39] Zimmerman, M. A. and G. J. Zeitz, "Beyond survival: Achieving new venture growth by building legitimacy", Academy of Management Review, 27(3), 2002, pp. 414-431

[40] Zott, C., and Q. N. Huy, "How entrepreneurs use symbolic management to acquire resources", Administrative Science Quarterly, 52(1), 2007, pp. 70-105 